\title{
Cytomorphological Evaluations of Malignant effusion in tertiary care center in central India- A hospital based study
}

\author{
Authors \\ Dr Jai Bharat Singh ${ }^{1}$, Dr Anand Bhadkariya ${ }^{2} *$, Dr Vijay Chaudhary ${ }^{3}$, \\ Dr Dimple A Bhadkariya ${ }^{4}$, Dr Arjun Singh ${ }^{5}$
}

${ }^{1}$ Pathologist District Hospital, Datia (M.P.)

${ }^{2}$ Associated Professor Department of Pathology Government Medical College, Datia (M.P.)

${ }^{3}$ Assistant Professor Department of pathology Government Medical College, Datia (M.P.)

${ }^{4}$ Senior Resident Department of Anesthesiology Government Medical College, Datia (M.P.)

${ }^{5}$ Professor \& Head Department of Pathology Government Medical College, Datia (M.P.)

*Corresponding Author

Dr Anand Bhadkariya

Associated Professor Department of Pathology Government Medical College, Datia (M.P.), India

\begin{abstract}
Introduction: Fluid can build up in the abdomen or chest, putting pressure on the internal organs. Examinations of the effusion fluid are very easy and relatively non-invasive technique for diagnosis. It has provided much information to helpful to patients diagnostically as well as therapeutically. The morphological examinations of the cells are helpful to diagnose as primary and secondary sites of malignancy that means its help prognostic evaluations of the diseases.

Material and Method: This prospective study was conducted in the Department of Pathology in Ruxmaniben Deepchand Gardi Medical College, Ujjain. Eighty-eight cases were included in this study.

Result: We studied 88 effusion fluids in which 37 (42.04\%) effusions were inflammatory with predominance of inflammatory cells to reactive mesothelial cells, followed by 20 (39.5\%) fluids showing malignant metastatic deposits. Grossly out of 88 effusions, 57 (64.0\%) fluids were straw colored while rest 31/88 (35.9\%) were reddish. Twenty-five malignant effusions were reddish appearance, while only six malignant effusions (19.3\%) were of straw-colored. Inflammatory fluids showed lymphocyte as the predominant cells.

Discussion: In present study cytological evaluation and routine staining of 88 cases with serous effusion was performed. On microscopy, apart from frankly malignant and other cases classified as inflammatory, or reactive effusion few cases were having variable number of cells with relatively large and rather hyperchromatic nuclei These cells were isolated or occurred in small clusters and could best be defined as suspicious. On white cell count, $68.1 \%$ effusion had white cell counts less than $1000 \mathrm{cells} / \mathrm{mm}^{3}$ and most of these effusions were either inflammatory or suspicious for malignancy. We found white cell count $>1000 / \mathrm{mm}^{3}$ in $51.61 \%$ (16 /31) of all malignant, effusion and 31.8\% (10/31) of malignant effusion were with cell count less than 1000 cells $/ \mathrm{mm}^{3}$.

Keywords: Effusion, Malignancy, Cytology, Cell morphology.
\end{abstract}




\section{Introduction}

Accumulations of the effusion fluid in the body occur many causes and many clinical conditions for example infection, traumatic, malignant etc. Fluid can build up in the abdomen or chest, putting pressure on the internal organs. Fluid accumulated in the body due to the cancerous causes this type of fluid collected between thin layers of tissue lining and outside of the organ, there is very difficult to clinicians and radiologist to detections of abnormalities and specific disease $^{[1]}$.

Examinations of the effusion fluid are very easy and relatively non-invasive technique to diagnosis. It has provided much information to helpful to patients diagnostically as well as therapeutically ${ }^{[2]}$. The morphologically examinations of the cells are helpful to diagnosed as primary and secondary sites of malignancy that means its help prognostic evaluations of the diseases $^{[3,4]}$.

Timely analyses of the effusion are more effective and preventive to disease it is simultaneously effective to other diagnostic procedure like biopsies in developing country it is easy to perform and less expensive

\section{Material and Method}

This prospective study was conducted in the Department of Pathology in Ruxmaniben Deepchand Gardi Medical College, Ujjain. The present study was conducted over a period of one and half years. Patients admitted in various departments of Chadrikaben Rashmikant Gardi hospital and Ujjain charitable trust hospital during with complaints of effusion or mass and having suspicion of malignancy were enrolled. Eightyeight cases were included in this study. All cases included in the present study were clinically suspicious for malignancy. All HIV positive patients and patient below 10 years of age were excluded from the study.

Effusion fluids were aspirated in the respective department and were sent to pathology laboratory for examination. Received specimen was checked for proper labeling and patient identification. Physical examination of specimen was done and following points were taken into consideration: volume, colour, appearance, turbidity and clot formation.

Relevant clinical history, physical examination and radiological findings were taken into account before the diagnosis was made.

Wet smear examination-Wet smear of fluid was prepared using 1\% methylene blue (Bio-Lab diagnostic)

Procedure

1. 2-3 drops of fluids was mixed with one drop of stain (methylene blue) and kept for few seconds to one minute for proper staining of cells.

2. One drop of the above mixture was taken on a glass slide and cover slip was placed over it and the slide was examined under low power followed by high power objective to see fungal hyphae and this method gives a three-dimensional view of cells and helps to differentiate mesothelial cells from the atypical or malignant cells.

Cell count-Manual cell count was performed using improved Neubauer chamber after mixing with WBCs diluting fluid.

Routine cytology examination

Smear preparation

1. Specimen was taken in a test tube and centrifuged at a speed of $3000 \mathrm{rpm}$ for 10 minutes.

2. Supernatant was separated, and used for the biochemical examinations; leaving only a small part of sediment in bottom of glass tube to used for smear preparations.

3. Slides were prepared, air dried and fixed by methanol one for cells morphology examinations and rest for immunocytochemical examinations.

Staining for cytology- Staining of slides for cytology was done by using Leishman's stain and Field stain A- B kit (Bio-Lab diagnostic). 
Microscopic examination- Stained smear were examined for intensity and quality of staining and were observed for. Cellularity

Slides were assessed for cellularity and graded on semi quantitative scales as-

a) More than 50-60 cells/hpf were equivalent to high cellularity;

b) $10-30$ cells/hpf were equivalent to moderate cellularity;

c) Less than 10 cells/hpf were equivalent to low cellularity.

Cell morphology

Slides were examined for

1. Type of cells

2. Cellular arrangement

3. Cell size: Size of the cells were approximately calculated by comparing it with the size of a small lymphocyte (6.7-7 micron)

4. Cell shape

5. Cytoplasmic character

6. $\mathrm{N}: \mathrm{C}$ ratio

7. Nuclear findings: Outline, chromatin pattern and nucleoli

The smears were classified as malignant when neoplastic cells were found, as suspicious when atypical cells were found and as inflammatory when inflammatory cells or no malignant or atypical cells were observed.

\section{Result}

Demographic characteristic of cases - The patients were of the age range from 19 to 77 years with the mean age of 51.9 years. Fifty eight percent cases were present in the older age groups $\left(5^{\text {th }}\right.$ and $6^{\text {th }}$ decade) and the male to female ratio was $1: 1.4$. In male patients, pleural effusions (64.2\%) constitute the most common type of effusions as compared to females as seen in Table 1.

Table 1- Demographic characteristic of cases in different effusions

\begin{tabular}{|l|c|c|c|c|}
\hline Effusion & Pleural & Ascitic & Pericardial & Total \\
\hline Age groups ( In years) \\
\hline $0-30$ & 10 & 05 & 00 & 15 \\
\hline $31-60$ & 36 & 15 & 03 & 54 \\
\hline$>60$ & 07 & 08 & 04 & 19 \\
\hline Gender \\
\hline Male & 34 & 07 & 00 & 41 \\
\hline Female & 19 & 21 & 07 & 47 \\
\hline Total & 53 & 28 & 07 & 88 \\
\hline
\end{tabular}

We found that the positivity for malignancies in effusions were higher in females as compared to males whereas in male patients inflammatory effusions were more common as seen in Table 2.

Clinical causes in different effusions - We studied 88 effusion fluids in which 37 (42.04\%) effusions were inflammatory with predominance of inflammatory cells with reactive mesothelial cells, followed by 20 (39.5\%) fluids showing malignant metastatic deposits as seen in Table 3.

Table 2- Demographic distribution of effusions according routine cytology diagnosis

\begin{tabular}{|l|c|c|c|c|}
\hline Effusion & Inflammatory & Suspicious & Malignant & Total \\
\hline Age groups ( In years) \\
\hline $0-30$ & 15 & 00 & 00 & 15 \\
\hline $31-60$ & 15 & 17 & 22 & 54 \\
\hline$>60$ & 07 & 03 & 09 & 19 \\
\hline Gender & 17 & 12 & 12 & 41 \\
\hline Male & 20 & 08 & 19 & 47 \\
\hline Female & 37 & 20 & 31 & 88 \\
\hline Total &
\end{tabular}


Table 3- Distribution of clinical causes in different effusions

\begin{tabular}{|l|c|c|c|c|}
\hline Diagnosis & Pleural Fluid & Ascitic fluid & Pericardial fluid & Total \\
\hline 1.Inflammatory(N=37) & 25 & 02 & 05 & 32 \\
\hline a. Tuberculosis & 02 & 00 & 00 & 02 \\
\hline b. COPD & 01 & 01 & 00 & 02 \\
\hline c. Chronic renal failure & 00 & 01 & 00 & 01 \\
\hline d. Gastroenteritis & 06 & 10 & 00 & 16 \\
\hline 2. Suspicious (N=20) & 02 & 02 & 00 & 04 \\
\hline a. Lung cusses & 13 & 00 & 00 & 13 \\
\hline b. Other & 02 & 01 & 02 & 05 \\
\hline 3. Malignant (N=31) & 00 & 04 & 00 & 04 \\
\hline a. Carcinoma lung & 00 & 04 & 00 & 04 \\
\hline b. Carcinoma breast & 02 & 03 & 00 & 05 \\
\hline c. Carcinoma GI Tract & 53 & 28 & 07 & 88 \\
\hline d. Carcinoma ovary & T. & & \\
\hline e. Other &
\end{tabular}

Out of 37 inflammatory fluids, 28 (75.67\%) fluids were from pleural cavity and remaining four fluids were ascitic. In 28 pleural fluids, 25 fluids were due to tuberculosis, two fluids were due to chronic obstructive pulmonary disease and remaining fluids were due to chronic renal failure with old pericarditis. Among inflammatory ascitic fluid (4/37), abdominal tuberculosis was the predominate cause $(2 / 4)$ for effusion.

Among 31 malignant effusions (metastatic deposits), seventeen fluids were from pleural fluids in which threaten (41.93\%) pleural fluids were due to the lung carcinoma, two fluids were due to carcinoma breast and remaining due to unknown primary. In twelve cases of ascitic fluid, four $(50 \%)$ fluids were due to carcinoma ovary and four case was due to carcinoma of gastrointestinal tract and rests were from unknown primary.

In present study, only two fluids were pericardial tap, both of which were malignant and there was a history of carcinoma breast in both the patients. Twenties effusion fluids were suspicious for malignancy in routine cytology. Eight fluids were pleural and twelve fluids were ascitic fluids.

Routine examination in effusions

Gross appearance

Grossly out of 88 effusions, 57 (64.0\%) fluids were straw coloured while rest 31/88 (35.9\%) were reddish. Twenty-five malignant effusions were reddish appearance, while only six malignant effusions $(19.3 \%)$ were of straw-colored. Out of 57 straw colored effusion only three showed atypical and suspicious cells while three fluids with reddish appearance showed atypical and suspicious cells. In inflammatory condition majority 33/37 (89.1\%) effusions were straw colored, while there was not much difference in the turbidity between benign and malignant.

Protein

Out of 88 effusion fluids majority of effusions $(83.7 \%)$ showed protein $<3 \mathrm{gm}$ and only fourteen $(15.9 \%)$ effusions showed protein $>3 \mathrm{gm}$.

Microscopic findings (Table 4)

Out of 88 serous effusion, 37 fluids were diagnosed as inflammatory, out of them 27 fluids showed low cellularity $\left(<500\right.$ cells $\left./ \mathrm{mm}^{3}\right)$ while only ten fluids showed high cellularity $(>500$ cells $/ \mathrm{mm}^{3}$ ). In effusions that were diagnosed as malignant, 16 cases showed high cellularity (> 500 cells $\left./ \mathrm{mm}^{3}\right)$. Fifteen cases showed low cellularity $\left(<500\right.$ cells $\left./ \mathrm{mm}^{3}\right)$. This corresponds with the known view that malignant fluids show high cellularity $\left(>500 \quad\right.$ cells $\left./ \mathrm{mm}^{3}\right), \quad$ and inflammatory fluids show low cellularity $(<500$ cells $/ \mathrm{mm}^{3}$ ). Among the atypical and suspicious cases moderate cellularity $\left(100-500\right.$ cell $\left./ \mathrm{mm}^{3}\right)$ was seen on $70 \%$ (14/20) effusion while only two $(2 / 20)$ cases were high of cellularity $\quad>500$ cells $/ \mathrm{mm}^{3}$ ). 


\section{JMSCR Vol||07||Issue||06||Page 248-255||June}

Table 4- Distribution of effusion according to routine cytology diagnosis

\begin{tabular}{|l|c|c|c|c|}
\hline Cytological finding & Inflammatory & Suspicious & Malignant & Total \\
\hline Cell count $\left(\right.$ Cells $\left./ \mathrm{mm}^{3}\right)$ & 00 & 00 & 00 & 00 \\
\hline$<10$ & 07 & 04 & 05 & 16 \\
\hline $10-100$ & 20 & 14 & 10 & 44 \\
\hline $100-500$ & 10 & 02 & 16 & 28 \\
\hline$>500$ & 08 & 01 & 01 & 10 \\
\hline Predominant cells & 25 & 05 & 08 & 38 \\
\hline \multicolumn{5}{|l|}{ Polymorph } \\
\hline Lymphocyte & 04 & 01 & 00 & 05 \\
\hline Eosinophil & 00 & 13 & 01 & 14 \\
\hline Mesothelial cells & 00 & 00 & 21 & 21 \\
\hline Malignant cells & 37 & 20 & 31 & 88 \\
\hline Total & \multicolumn{5}{|l}{}
\end{tabular}

Inflammatory fluids showed lymphocyte as the predominant cells (Shows Fig No.1). Out of the 31 cases of malignant fluids, $21(67.7 \%)$ showed malignant cells as the predominant cells (Shows Fig No.3\&4) whereas nine (29.4\%) cases showed inflammatory cells as the predominant cells suggesting presence of secondary infection. Of the suspicious cases, 65\% showed mesothelial as predominant cell (Shows Fig No.2), proposing that chronic inflammation might be coexisting along with atypical cells.

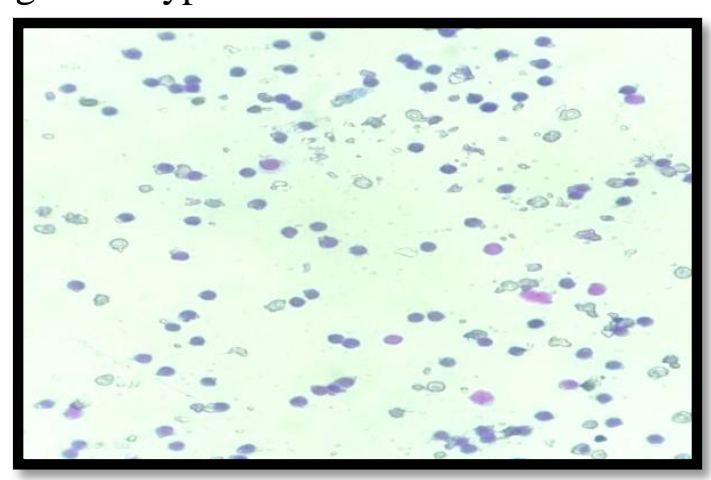

Fig 1: Inflammatory smear- predominance of chronic inflammatory cells. from effusion (x40).

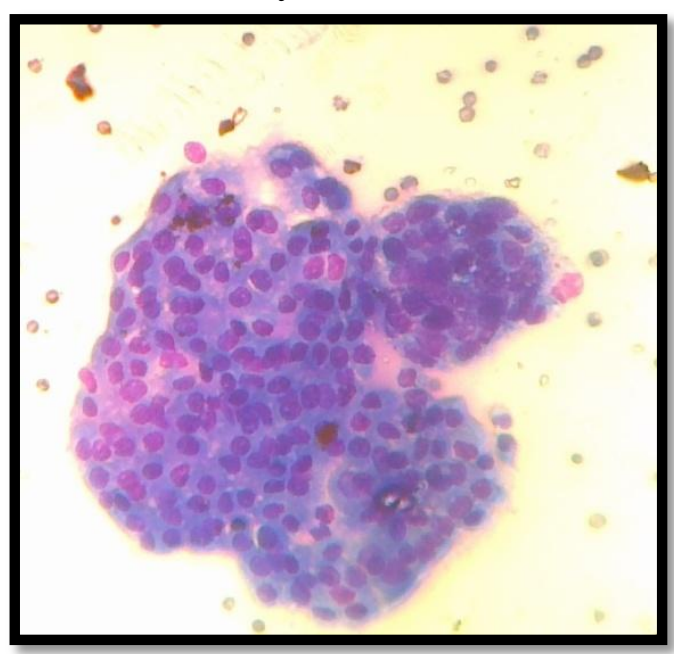

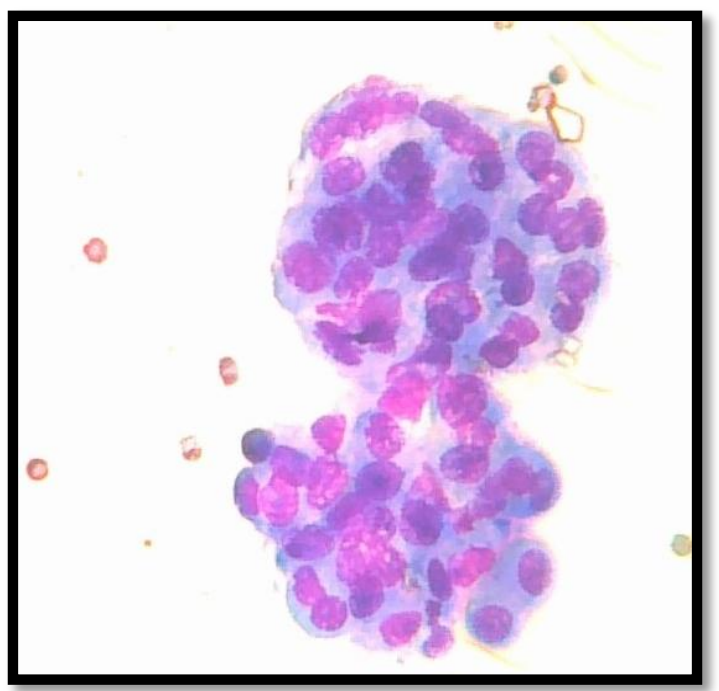

Fig 2: Reactive mesothelial cells of pleural fluid arranged in cluster $(\mathrm{x} 40)$

\section{Adenocarcinoma}
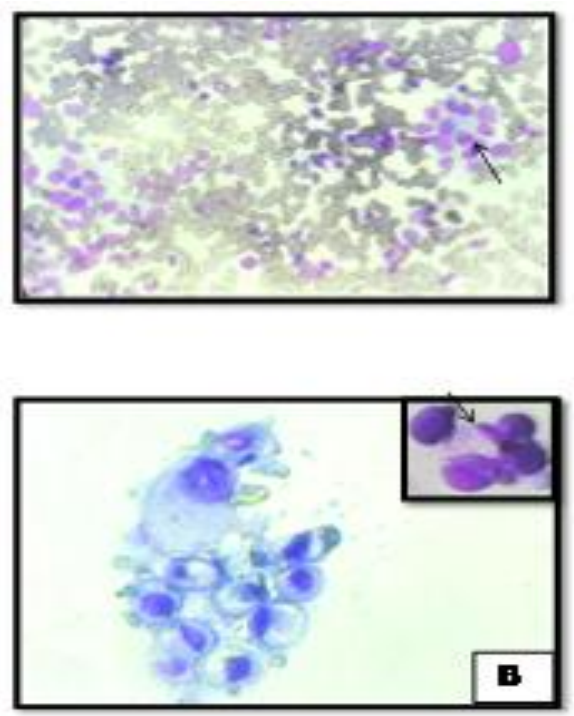

Fig 3, 4: Adenocarcinoma cells arranged in glandular pattern (from effusion $\mathrm{x} 40$ ). In fig. B Show signet ring cells of adenocarcinoma and inset show ring shaped adenocarcinoma cells 


\section{Discussion}

The Diagnostic accuracy of the cytological examination of the fluid may be more effective in comparison to the fine needle cytology because aspiration cytology represent a much larger surface area than that obtained by needle biopsy. ${ }^{[3,4]}$ The present study deal with accuracy of diagnosis on the basis of clinical presentations and cell cytology.

Effusions of serous cavities are commonly encountered in clinical practice and the causes for which range from inflammatory, surgical, traumatic to disseminated carcinomatosis. Precise cytological evaluation whether it is due to benign or malignant cause is essential for prognostic as well as for therapeutic point of view. The percentage of reported cytologically positive diagnosis of malignant effusions and aspirates varies from 10 to $49 \%{ }^{[5,6]}$. The clinical presentation of malignant tumor is an essential advantage to a cytopathology and may increase diagnostic yield many times ${ }^{[4]}$.

The purpose of this study was to compare the morphological features with routine cytological pattern of cells in malignant and benign effusions and to assess their potential value in routine diagnostic cytology. The use of the morphological features has been advocated by several workers as helpful in often difficult differential diagnosis from reactive effusion or from metastatic spread from lung adenocarcinoma. It has been shown that morphology of the cells is an important diagnostic tool for differential diagnosis of various tumors.

In present study cytological evaluation and routine staining of 88 cases with serous effusion was performed. Grossly, the effusions studied in the present study either had straw colour or hemorrhagic appearance. Most of the strawcoloured fluids $(89.1 \%)$ were inflammatory or suspicious effusions for malignancy on further examination. About $76.4 \%$ of hemorrhagic fluids were diagnosed as malignant. This difference was statistically significant $(\mathrm{p}<0.001)$. The remaining cases of hemorrhagic effusion were due to benign causes like trauma, pulmonary tuberculosis and inflammatory infarction. Thus, in our study hemorrhagic effusions are more like to be caused by either primary or secondary malignancies. Various studies also showed that hemorrhagic effusions are more likely due to primary or secondary malignancies ${ }^{[7,8]}$. But all hemorrhagic effusion need not be due to malignancy and nonhemorrhagic fluids can have malignancy.

On microscopy, apart from frankly malignant and other cases classified as inflammatory, or reactive effusion few cases were having variable number of cells with relatively large and rather hyperchromatic nuclei These cells were isolated or occurred in small clusters and could best be defined as suspicious. Similar findings have been reported by Boon et $\mathrm{al}^{[9]}$ and Hilborne et $\mathrm{al}^{[10]}$. In our series, such diagnostic problem was reported in $35.2 \%$ of all effusion sent for cytological examination. To et al reported the same proportion of suspicious effusion in their series of effusion studied ${ }^{[6]}$.

On white cell count, $68.1 \%$ effusion had white cell counts less than 1000 cells $/ \mathrm{mm}^{3}$ and most of these effusions were either inflammatory or suspicious for malignancy. We found white cell count $>1000 / \mathrm{mm}^{3}$ in $51.61 \%(16 / 31)$ of all malignant, effusion and $31.8 \% \quad(10 / 31)$ of malignant effusion were with cell count less than 1000 cells $/ \mathrm{mm}^{3}$. Thus the total white cell count cannot be used alone as a criteria for differentiating fluids into benign or malignant. Smith \& Kjeldsberg proposed one criteria for categorizing an effusion as an exudates with cell count $>1000$ cells $/ \mathrm{mm}^{3}$ and these exudates can be caused by both benign and malignant processes. According to some researchers total and differential cell count on effusions are of little diagnostic value for categorizing fluid as benign or malignant. In addition, according to Dines and Coworkers the only useful finding to define an effusion is the presence of neoplastic cells ${ }^{[11,12]}$.

Tuberculosis is the most common clinical diagnosis in inflammatory conditions in effusions. In these condition lymphocytes are the predominant cells on differential count of fluid 
cytology. The present study corroborated with the study done by Epstein et al in 1987 they show the majority of tuberculous effusion had more than $50 \%$ lymphocytes. This is in concordance with other researchers ${ }^{[13,14]}$.

In the present studies we found that high malignancy ratio in female comparison to male (1:1.5) this study correlated with study done by Sears et al in 1987. ${ }^{[9]}$

\section{Conclusions}

In the present study, we conclude that malignant effusions are more reddish that is hemorrhagic while benign effusions tend to be straw colour. The total cell count does not show any significant difference between benign and malignant effusions. Among the inflammatory conditions in effusion, tuberculosis is the most common clinical diagnosis. Cytomorphology remains the most important and reliable diagnostic tool in delineating benign from malignant conditions with particular emphasis on the nuclear morphology of benign and malignant cells.

The physical and morphological examination of the cells is a complete diagnostic technique, which aims to evaluate of fluid at pointing out the etiology of effusion, outcome of the disease, stage of the disease and prognostic value of the disease.

\section{References}

1. "NCI Dictionary of Cancer Terms". NCI. 2011-02-02. Retrieved 21 December 2018

2. Cheson BD. Clinical utility of body fl uid analysis. Clin Lab Med 1985;5:195-208.

3. Frist B, Kahan AV, Koss LG. Comparison of the diagnostic values of biopsies of the pleura and cytologic evaluation of pleural fl uids. Am J Clin Pathol 1979;72:48-51.

4. Sherwani R, Akhtar K, Naqvi AH, Akhtar $\mathrm{S}$, Abrari A, Bhargava R. Diagnostic and prognostic signifi cance of cytology in effusions. J Cytol 2005;22:73-7.

5. Khushwah R,Shashikala P, Hiremath $\mathrm{S}$, Basavaraj FG; Cell in pleural fluid and their value in differential diagnosis.
Journal of cytology : Volume 25:Issue 4;2008.

6. Alusi FA, pleural effusion in Iraq. A prospective study of 100 cases Thorax 1986; 41:29223.

7. Leila Antonangelo et al clinical and laboratory parameters in the differential diagnosis of pleural effusion secondry to tuberculosis or cancer. CLINICS 2007; 62(5):585-90.

8. Smith G P, Kjeldsberg LR. Cerebrospinal, synovial and serous boddy fluids. In: John Bernard Henry, editior. Clinical diagnosis and management by laboratory method, 19thrd. W.B. Saunders Company; 1996;pp 457-482.

9. Getachew A, Tesfahunegn Z. Is fine needle aspiration cytology a useful tool for the diagnosis of tuberculous lymphadenitis. East Afr Med J. 1999 May;76 (5):2603. [ PMID:10750505 Abstract]

10. Lai RS, Chen CC, Lee PC, Lu JY. Evaluation of cytokeratin 19 fragment (CYFRA 21-1) as a tumor marker in malignant pleural effusion. Jpn J Clin Oncol. 1999 Sep;29(9):421-4.[ PubMed 10563194 Abstract].

11. Margaritescu Cl, Mogoanta L., Manescu P, Cristiana S, Pirici D,Streba L, Mercut D. The immunohistochemical profile of the adenocarcinoma of upper gastric pole. Romanian Journal of Morphology and Embryology 2007, 48(3):215-235.

12. Kaufmann o,Fietze E,Mengs J,Dietel M.Value of p63 and cytokeratin 5/6immunohistochemical markers for the differential diagnosis of poorly differentiated and undifferentiated carcinomas. Anatomic pathology 2001

13. Dines DE, Pierre RV, Franzel SI. The value of cells in pleural fluid in differential diagnosis. Mayo clin proc 1975; 50:571572. 
14. Prasoon D. Acid-fast bacilli in fine needle aspiration smears from tuberculous lymph nodes. Where to look for them. Acta Cytol. 2000 May-Jun;44(3):297-300.[ PMID:10833981 Abstract]. 